\title{
Aos leitores
}

DOI: $10.1590 / 1809-5844201711$

\section{Maria Ataide Malcher}

(Universidade Federal do Pará, Instituto de Letras e Comunicação, Programa de Pós-Graduação Comunicação, Cultura e Amazônia. Belém - PA, Brasil)

\section{Iluska M. da Silva Coutinho}

(Universidade Federal de Juiz de Fora, Faculdade de Comunicação, Programa de Pós-Graduação em Comunicação. Juiz de Fora - MG, Brasil)

Inauguramos com este primeiro número, a publicação da Intercom - Revista Brasileira de Ciências da Comunicação no ano de 2017. Um ano conturbado para o país e um contexto que aponta para o recuo ou a extinção de garantias alcançadas por batalhas travadas ao longo de décadas em vários campos. Um momento que, sem dúvida, fragiliza a jovem democracia brasileira, colocando em risco direitos sociais fundamentais ao equilíbrio social. Orientando o foco ao nosso lugar de fala, assistimos em pouco tempo o desmonte dos Ministérios da Ciência e Tecnologia e das Comunicações, tendo como resultado uma fusão que, para os envolvidos, é no mínimo um retrocesso nas discussões de décadas no Brasil. Nessa nova estrutura, se voltarmos nossos olhares ao lugar da Educação, o receio parece tomar conta de nossas mentes e corações. O que nos mostra esse momento vivido? O que podemos fazer e como faremos para superá-lo? Perguntas que não serão respondidas neste espaço e tão pouco de forma simples, mas entendemos que, para encontrar soluções, precisamos realizar, cada vez mais e melhores, problematizações do que está acontecendo. Nossa melhor trincheira deve ser a construção do conhecimento científico e é, de fato, desse lugar que acreditamos ser possível compreender os reveses históricos que estamos vivendo e de onde conseguimos dar melhores e maiores contribuições. Se assim o é, sigamos em frente, vigilantes, críticos, resistentes e combativos, empunhando nossas "maiores armas" para compreensão do contemporâneo e do papel fundamental da comunicação na construção dos processos sociais.

Com esse espírito, apresentamos ao leitor as contribuições de trinta pesquisadores, concretizadas em onze artigos, uma entrevista e quatro resenhas de livro. Um exemplo sintético do momento vivido ao colocar em diálogo diferentes gerações, conectando localidades distantes, fazendo circular o que antes ficava restrito ao local de produção.

Oferecemos para abertura da leitura, no eixo Inovação, Tecnologia e Reconfigurações, três artigos dedicados à discussão de novas formas de pensar, fazer e compreender fenômenos contemporâneos. Formas que configuram produções e processos diferenciados, como pode 
ser percebido em Narrativas webjornalísticas como elemento de inovação: casos de Al Jazeera, Folha de S.Paulo, The Guardian, The New York Times e The Washington Post, de Raquel Ritter Longhi e Ana Marta M. Flores, ao apresentar as inovações estudadas no jornalismo. Uma análise que aponta para uma transformação no jornalismo, a qual pode fortalecer ou até mesmo reinventar essa que é uma das práticas comunicacionais extremamente necessárias aos tempos vividos. Da mesma forma, temos em $O$ quarto narrador, a midiatização e as narrativas da violência, de Demétrio de Azeredo Soster, uma análise das narrativas da mídia, que se reafirma na atualidade como quarto narrador da violência. Um tema destacado na agenda de discussão, uma das grandes ameaças à comunicação e, portanto, algo que desestabiliza a ordem social e complexifica ainda mais o presente. No artigo Excurso sobre media, tecnologia e trabalho, Esser Silva convida o leitor à reflexão sobre as alterações no mundo do trabalho a partir das configurações estabelecidas pela tecnologia. O texto apresenta uma análise do mundo do trabalho de Portugal, mas sem dúvida oferece uma rica contribuição para pensarmos o lugar do trabalho na tessitura do comunicacional em qualquer "aldeia global”. Uma reflexão que fornece mais subsídios para nossas preocupações diante de tantas mudanças na legislação trabalhista no Brasil.

No eixo Consumo, Público e Relacionamentos, reunimos artigos dedicados às estratégias para envolvimento dos públicos com diferentes produtos. Nessa perspectiva, fica evidente a necessidade de entendermos os processos de consumo, não limitados à posse de produtos e/ou serviços. Como defendido pelos estudiosos da área, "o consumo serve para pensar”, sendo assim, a partir dele podemos compreender as inúmeras teias que tecem o social e dão significado ao vivido. O início dessa discussão se dá com o artigo Atenção, memória e percepção: uma análise conceitual da Neuropsicologia aplicada à propaganda e sua influência no comportamento do consumidor, de Ana Cláudia Braun Endo e Marcio Antonio Brás Roque. Nele encontramos interessante experimentação que evidencia a contribuição dos estudos do comportamento do consumidor para compreensão do processo de estímulo-resposta. Sabemos que o processo comunicacional não se resume a uma fórmula e, muito menos, ocorre de forma linear, mas temos consciência que o estímulo é também um elemento desse processo. Em Os arquétipos na gestão de uma marca: aplicação à marca líder do mercado de cervejas brasileiro, Daniel Kamlot e Pedro de Queiroz Calmon trazem contribuições valorosas para compreendermos as narrativas publicitárias construídas a partir dos usos dos arquétipos, demonstrando os elementos destacados pelos consumidores em anúncios de cervejas. Fechando esse eixo, temos uma discussão dos níveis de interatividade percebidos em sites institucionais. Em Análise da participação dos usuários nos conteúdos de sites institucionais a partir dos níveis de interatividade, Victor Nassar e Milton Vieira apresentam as diferentes formas de relacionamento dos consumidores a partir dos veículos institucionais. 
A importância do consumo para discussões comunicacionais também é evidenciada no artigo A cartografia de um campo: singularidades e possibilidades nas relações entre religião e consumo nos trabalhos desenvolvidos na Comunicação, de Karla Regina Macena P. Patriota, Carolina Cavalcanti Falcão e Emanuelle Gonçalves Brandão Rodrigues. Este, por sua vez, integrante do eixo Reflexões Epistemológicas da Comunicação, apresenta uma cartografia dos estudos de Comunicação na interface entre consumo e religião. Duas esferas de construção de significados cada vez mais interligadas. As autoras oferecem para crítica o resultado de um exercício a partir da metáfora das vias urbanas, tomadas de empréstimo para desenhar os fluxos dos estudos cartografados. Acompanhando esse movimento reflexivo e provocativo, temos o artigo Comunicação sem anestesia, de Laan Mendes de Barros, com um convite a pensarmos o lugar da experiência estética no processo comunicacional.

O último eixo temático deste número é Mulheres, Mídias e Questões de Gênero. Guardadas as devidas proporções, esse eixo retoma assuntos tratados em eixos anteriores, mas com a proposta de guiar as reflexões a partir da figura da mulher. No artigo Comunicação, migrações e gênero: famílias transnacionais, ativismos e usos de TICs, Denise Cogo apresenta reflexão sobre o papel do consumo e dos usos das Tecnologias da Comunicação e Informação (TICs) nas experiências migratórias e, em especial, nas relações de gênero desse contexto. Em Mulheres rurais e seus usos mediados das TICs: tensionamentos e permanências nas relações de gênero, de Ana Carolina D. Escosteguy, Lírian Sifuentes e Aline Feijó Bianchini, é apresentada experiência de pesquisa na qual as práticas cotidianas de mulheres agricultoras em relação às TICs são analisadas a partir do mapa das "mediações comunicativas da cultura” de Jesús Martín-Barbero. Com Homens e mulheres cientistas: questões de gênero nas duas principais emissoras televisivas do Brasil, de Vanessa Brasil de Carvalho e Luisa Massarani, o convite ao leitor é para refletir sobre os elementos que constituem a representação da mulher como cientista na sociedade, a partir do que é veiculado na programação televisiva brasileira de circuito aberto.

Para corroborar com a necessidade de percebemos a força do local, temos a entrevista Mídia local: valor e pesquisa, com Robert G. Picard, concedida a Jacqueline da Silva Deolindo, João Guilherme Bastos dos Santos e Cynthia Maciel Duarte. Nela, o entrevistado, especialista em Economia e Gestão de Mídia, discute o importante papel da mídia regional no mercado, tendo como ponto de partida as realidades norte-americanas e europeias, o que nos auxilia a pensar a questão em um contexto nacional.

Finalizando este número apresentamos resenhas de livros bastante convidativos para o momento vivido, como é o caso das obras: Estado de Crise, de Zygmunt Bauman e Carlo Bordoni, resenhada por Ingrid Gomes e Suelen Aguiar da Silva; Comunicação popular, alternativa e comunitária: um olhar sobre 40 anos de pesquisas no Brasil, de Maria Alice Campagnoli Otre, resenhada por Nívea Canalli Bona; Filmar operários: registro e ação 
política dos cineastas durante a ditadura militar no Brasil, de Marcos Corrêa, resenhada por Maria Alice Campagnoli Otre e Curso Básico de Teorias da Comunicação, de Vera França e Paula Simões, resenhada por Marcilene do Carmo de Oliveira Miranda e Suzana Cunha Lopes.

Esperamos que as opções de leitura apresentadas neste número contribuam para o alargamento do nosso olhar, na tentativa de vislumbrarmos de modo mais claro as contribuições que o comunicacional tem a oferecer para à compreensão do momento atual de nossa sociedade.

Registramos ainda que a partir desta edição a professora Iluska Coutinho deixa de ser editora associada para se tornar editora da Revista, a quem damos boas-vindas. Não podemos deixar de registrar nossos mais sinceros agradecimentos aos autores, pareceristas, corpo editorial e todos que contribuem com a RBCC.

Da mesma forma, para nós é fundamental registrar que após uma década de trabalho para alçar a RBCC ao local onde se encontra, a professora Cicilia Peruzzo deixa de assinar o editorial da revista e passa a compor o Conselho Editorial Científico. Ao entregar o bastão de forma tão generosa e competente, nos deixa com uma responsabilidade muito grande: levar à frente o alcançado em sua gestão. Sabemos, no entanto, que poderemos sempre contar com ela e com todos que construíram e constroem a Intercom - Revista Brasileira de Ciências da Comunicação. Por isso, sabemos que conseguiremos seguir em frente.

Boa leitura! 